\title{
COVID-19 and Social Sciences
}

\author{
Carlos Miguel Ferreira ${ }^{1,2}$ and Sandro Serpa ${ }^{3,4,5, *(D)}$ \\ 1 Interdisciplinary Centre of Social Sciences-CICS.NOVA, 1649-026 Lisbon, Portugal; carlos.ferreira@eshte.pt \\ 2 Estoril Higher Institute for Tourism and Hotel Studies, 1069-061 Lisbon, Portugal \\ 3 Department of Sociology, Faculty of Social and Human Sciences, University of the Azores, \\ 9500-321 Ponta Delgada, Portugal \\ 4 Interdisciplinary Centre of Social Sciences-CICS.UAc/CICS.NOVA.UAc, University of the Azores, \\ 9500-321 Ponta Delgada, Portugal \\ 5 Interdisciplinary Centre for Childhood and Adolescence-NICA-UAc, University of the Azores, \\ 9500-321 Ponta Delgada, Portugal \\ * Correspondence: sandro.nf.serpa@uac.pt
}

Received: 14 December 2020; Accepted: 14 December 2020; Published: 16 December 2020

The COVID-19 pandemic (caused by the Severe Acute Respiratory Syndrome Coronavirus 2, SARS-CoV-2) is having profound effects on all dimensions of life, such as the individual, social, cultural, public health, and economic dimensions [1,2]. However, the place ascribed to social sciences and their contributions is not sufficiently valued, as may be seen in the bibliographic study by Aristovnik, Ravšelj, and Umek [3] (pp. 1 and 22) in an extensive yet very current and illuminating citation:

The empirical results indicate the domination of health sciences in terms of number of relevant publications and total citations, while physical sciences, social sciences, and humanities lag behind significantly. Nevertheless, there is evidence of COVID-19 research collaborations within and between different subject area classifications, with a gradual increase in the importance of non-health scientific disciplines. The findings emphasize the great need for a comprehensive and in-depth approach that considers various scientific disciplines in COVID-19 research so as to benefit not only the scientific community but evidence-based policymaking as part of efforts to properly respond to the COVID-19 pandemic. [ . . . ] In order to address the economic, socio-cultural, political, environmental, and other (non-medical) consequences of the COVID-19 pandemic, in the near future, COVID-19 must appear higher up on the research agenda of non-health sciences, particularly social sciences and humanities.

This relevance of the relationship between COVID-19 and social sciences results from the fact that the disease is shaped by cultural elements that are studied in social sciences. Ferreira and Serpa [4] maintain, in this regard, that epidemics and pandemics have varied effects on societies. These effects are noticeable at the level of societies' beliefs, institutions, and social, demographic, economic, and political structures. Regarding the notion of contagion, also analyzed by the authors, the articulation between impurity, purification, and interdiction of contact, as a result of the belief in contagion, embodies the symbolic management of both internal and external dangers. This belief that purification emerges from the interdiction of contact coerces healthy individuals to avoid any physical and social approach with patients and other individuals perceived as dangerous in terms of disease transmission [4].

In this context, it was deemed pertinent to suggest to Societies the Special Issue COVID-19 and Social Sciences, justified by the fact that the potential contribution of social sciences is not being sufficiently mobilized. This special issue aims to:

[ ... ] contribute to advancing our understanding of the heuristic capacity of Social Sciences as a fundamental tool in the analysis of cognitive assessments and collective behaviors developed in the pandemic caused by COVID-19 and the implications of the exponential increase of social interactions and spatial, economic, and societal dynamics, at various scales, in the post-pandemic future. [5] 
For this Special Issue, COVID-19 and Social Sciences, 14 manuscripts were received, having been selected for publication after several improvements resulting from a rigorous reviewing process, and six papers that focus on different perspectives and are relevant contributions. A brief presentation of each published article follows.

Rudnick [6], in "Social, Psychological, and Philosophical Reflections on Pandemics and Beyond", demonstrates the relevance of several social, psychological, and philosophical issues underlying the COVID-19 pandemic, such as the moral distress of healthcare providers when they have to make decisions about the life or death of patients or related to mental health amplified by quarantine and prophylactic isolation, as well as the need to provide society with additional protection for socially disadvantaged people.

Arias-Maldonado [7], in "COVID-19 as a Global Risk: Confronting the Ambivalences of a Socionatural Threat", proposes to categorize the COVID-19 pandemic as a particular kind of risk that combines premodern and modern features; it takes place in the Anthropocene but is not of the Anthropocene.

Ferreira, Sá, Martins, and Serpa [8] present "The COVID-19 Contagion-Pandemic Dyad: A View from Social Sciences". This manuscript offers a presentation of potential contributions from several specific social sciences, analyzing the analytical potential of social sciences in an informed understanding of the challenges that the COVID-19 pandemic poses to society at the economic, social, and health levels, but which, however, has not been sufficiently mobilized by policymakers.

In turn, Tobin, Mavrommati, and Urban-Rich [9], in "Responding to Social Distancing in Conducting Stakeholder Workshops in COVID-19 Era", offer a contribution on how academic research in the social sciences can, needs to, and must adapt to the compliance with the COVID-19 pandemic control rules. To this end, the authors reflect on real situations of workshops through the mobilization of technology that allows, simultaneously, to satisfy requirements such as social/physical distance. This virtual stakeholder engagement poses potential challenges, several of which are discussed in this article.

Grabowski, Meldgaard, and Hulvej Rod [10], in "Altered Self-Observations, Unclear Risk Perceptions and Changes in Relational Everyday Life: A Qualitative Study of Psychosocial Life with Diabetes during the COVID-19 Lockdown", put forth a study on the psychosocial effects of the conditions for living with a chronic disease such as diabetes in the context of a COVID-19 lockdown in the Danish context.

Finally, Ferri, Grifoni, and Guzzo [11], in “Online Learning and Emergency Remote Teaching: Opportunities and Challenges in Emergency Situations", contribute with an article that aims to analyze the opportunities and challenges of remote education in the context of the COVID-19 emergency, culminating in the analysis of various technological, pedagogical, and social challenges that emerge from this study.

Scientific work does not happen in an isolated or individual way, and hence, we would like to thank all the stakeholders who contributed to the accomplishment of this project that is now offered to the reader. We begin by thanking Dr. Gregor Wolbring, Societies Editor-in-Chief, for the confidence placed on us by accepting our call for proposals for this Special Issue. An acknowledgment is due to all authors who submitted manuscripts, reviewers, whose evaluation work was essential and critical to the quality of publications, and the entire editorial office; their professionalism enabled the materialization of this final result.

In conclusion, if any writing becomes the property of the reader after its publication, we would like to believe that this Special Issue COVID-19 and Social Sciences could be yet another vehicle demonstrating the potential of social sciences in developing the understanding how COVID-19 is perceived and experienced. This knowledge is pivotal, for example, in the definition and application of measures to be taken to control the pandemic. Even now that the availability, distribution, and application of vaccines are around the corner, social sciences can make an important contribution to the success of this process. 
Funding: This research was funded by the University of the Azores, Interdisciplinary Centre of Social Sciences-CICS.UAc/CICS.NOVA.UAc, UID/SOC/04647/2020, with the financial support of FCT/MEC through national funds and, when applicable, co-financed by FEDER under the PT2020 Partnership Agreement.

Conflicts of Interest: The authors declare no conflict of interest.

\section{References}

1. Sá, M.J.; Serpa, S. The global crisis brought about by SARS-CoV-2 and its impacts on education: An overview of the Portuguese panorama. Sci. Insights Educ. Front. 2020, 5, 525-530. [CrossRef]

2. Sá, M.J.; Serpa, S. The COVID-19 pandemic as an opportunity to foster the sustainable development of teaching in higher education. Sustainability 2020, 12, 8525. [CrossRef]

3. Aristovnik, A.; Ravšelj, D.; Umek, L. A bibliometric analysis of COVID-19 across science and social science research landscape. Sustainability 2020, 12, 9132. [CrossRef]

4. Ferreira, C.M.; Serpa, S. Contagions: Domains, Challenges and Health Devices. Acad. J. Interdiscip. Stud. 2020, 9, 1-14. [CrossRef]

5. Ferreira, C.M.; Serpa, S. Special Issue "COVID-19 and Social Sciences" 2020. Available online: https: //www.mdpi.com/journal/societies/special_issues/COVID-19_social_sciences (accessed on 11 December 2020).

6. Rudnick, A. Social, psychological, and philosophical reflections on pandemics and beyond. Societies 2020, 10, 42. [CrossRef]

7. Arias-Maldonado, M. COVID-19 as a global risk: Confronting the ambivalences of a socionatural threat. Societies 2020, 10, 92. [CrossRef]

8. Ferreira, C.M.; Sá, M.J.; Martins, J.G.; Serpa, S. The COVID-19 contagion-pandemic dyad: A view from social sciences. Societies 2020, 10, 77. [CrossRef]

9. Tobin, C.; Mavrommati, G.; Urban-Rich, J. Responding to Social Distancing in Conducting Stakeholder Workshops in COVID-19 Era. Societies 2020, 10, 98. [CrossRef]

10. Grabowski, D.; Meldgaard, J.; Hulvej Rod, M. Altered self-observations, unclear risk perceptions and changes in relational everyday life: A qualitative study of psychosocial life with diabetes during the COVID-19 lockdown. Societies 2020, 10, 63. [CrossRef]

11. Ferri, F.; Grifoni, P.; Guzzo, T. Online learning and emergency remote teaching: Opportunities and challenges in emergency situations. Societies 2020, 10, 86. [CrossRef]

Publisher's Note: MDPI stays neutral with regard to jurisdictional claims in published maps and institutional affiliations.

(C) 2020 by the authors. Licensee MDPI, Basel, Switzerland. This article is an open access article distributed under the terms and conditions of the Creative Commons Attribution (CC BY) license (http://creativecommons.org/licenses/by/4.0/). 